\title{
Individual-based modelling of fish population dynamics in the river downstream under flow regulation
}

\author{
Weifeng Li, Rui Han, Qiuwen Chen*, Shen Qu, Zhongni Cheng \\ Research Center for Eco-Environmental Sciences, Chinese Academy of Sciences, Shuangqing Road 18, Haidian District, Beijing 100085, China
}

\section{A R T I C L E I N F O}

\section{Article history:}

Received 21 January 2009

Received in revised form 25 December 2009

Accepted 27 December 2009

\section{Keywords:}

Reservoir operation

Fish population dynamics

Water quality module

Individual-based module

Lijiang River

\begin{abstract}
A B S T R A C T
Due to the operations of hydraulic structures, the flow regimes in downstream are dramatically altered, causing serious impacts on the aquatic ecosystem. To investigate the effects on the fish population dynamics, this study developed a model that integrated a two-dimensional water quality module with an individualbased fish module. Through field surveys and laboratory flume experiments, the preference curves of the studied fishes to the flow conditions were defined. Compared to the previous version of the model, the main improvements consist in the features of population grouping and escaping, space competition, and different adaptabilities to environment changes. The developed model was applied to a compound channel of the Lijiang River in the southwest China, where the flow has been largely modified by the upstream Qingshitan Reservoir. Two dominant species that are grass carp (Ctenopharyngodon idellus) and crucian carp (Carassius auratus) were modelled. The model was validated by the historical fish survey data and the field observations conducted during the study. The scenario analysis showed that, if only the flow aspect was concerned, the flow regulations had positive effects on the non-migrating fish grass carp, but had little impact on crucian carp. In particular, the present operation scheme from early April to end of May should be improved. The methodologies developed in the research can provide support to optimize reservoir operation schemes and improve river management.
\end{abstract}

(c) 2010 Elsevier B.V. All rights reserved.

\section{Introduction}

In the recent decades, water resource exploitation and hydropower development have severely damaged the structure and function of river ecosystem. Following the rapid increase of public awareness of ecological aspects, there are strong demands to quantitatively investigate other than qualitatively assess the impacts of reservoir operations and seek for implementable remediation measures (Nagaya et al., 2008; Tollefson, 2008). To achieve such objectives, in-situ monitoring and numerical simulation are usually adopted to track the changes of the aquatic species populations. Because of the high cost and the long period of monitoring campaign, numerical simulation based on physical mechanisms has become the major method. Fish population dynamics is seen as an important indicator of aquatic environment changes, thus attracts great interests from the modelling community (Liem, 1995; Dong and DeAngelis, 1998; Holm et al., 2001; Goodwin et al., 2006; Charles et al., 2008).

Due to high complexity, knowledge to ecosystem is mostly semiempirical. Meanwhile, the available data of ecosystem are usually

\footnotetext{
* Corresponding author.

E-mail address: qchen@rcees.ac.cn (Q. Chen).
}

limited and sparse. Therefore, the development of fish population dynamic model is a challenging effort. The conventional population models are mainly aggregated and conceptually based. Such models often oversimplify or even neglect the individual differences and local interactions (Kitazawa et al., 2008; Chen et al., 2009a). The fish habitat models describe the suitability of the aquatic environment for the specific species (Bovee, 1982), thus they can be applied to analyze and assess the ecological effects of river developments and restorations (Shuler and Nehring, 1993; Shields et al., 1997; Duel et al., 2002). However, these habitat models are in general static that fail to present the processes.

Facilitated by the fast advancement of computer technology and spatial data collection, individual-based models were largely motivated (Rose et al., 1993; Clark and Rose, 1997; Morales-Chaves, 2004). Compared to lumped models, they are discrete in time, space and model variables (DeAngelis and Gross, 1992; Chen, 2004). These models take each individual as the object and apply differential equations to describe the changes of the properties such as age, length and weight and the actions of movement, predation and escaping (DeAngelis and Gross, 1992; Van Winkle et al., 1993; DeAngelis et al., 1994; Tyler and Rose, 1994; Dong and DeAngelis, 1998) to obtain the global spatial-temporal patterns (Dong and DeAngelis, 1998; Holm et al., 2001). It is similar to the Lagrangian approach in fluid mechanics. Owing to the special ability, individual-based approach has been 
widely applied to fish population modelling (Goodwin et al., 2006; Charles et al., 2008; O'Callaghan and Gordon, 2008).

This research took a compound channel of the Lijiang River as the study case, and developed an individual-based fish module, which was then integrated with a two-dimensional water quality module. The model was applied to investigate the impacts of the upstream Qingshitan Reservoir operations on the downstream fish population dynamics, to provide suggestions to optimize the flow regulations for ecological concerns.

\section{Model developments}

\subsection{Model framework}

The developed model includes a two-dimensional water quality module and an individual-based fish module (Fig. 1). The water quality module provides the external forcing to the fish module. For the time being, the effects of fish population on the water quality are not considered.

There are several factors affecting fish population dynamics that mainly include the flow (water depth and velocity) and water quality (water temperature, dissolved oxygen and suspended substance). The reservoir regulations dramatically change the downstream hydrological regimes that result in strong seasonal alternations of shallow regions, deep regions and local flow fields. In addition, the reservoir operations are usually accompanied by the release of clean, cold and low oxygen water.

\subsection{The flow model}

The flow field of the studied compound channel was simulated by the two-dimensional shallow water equations that are given as:

$\frac{\partial H}{\partial t}+\frac{\partial(h u)}{\partial x}+\frac{\partial(h v)}{\partial y}=Q_{a}$

$\frac{\partial u}{\partial t}+u \frac{\partial u}{\partial x}+v \frac{\partial u}{\partial y}=-\frac{1}{\rho_{0}} \frac{\partial p}{\partial x}+f v+v\left(\frac{\partial^{2} u}{\partial x^{2}}+\frac{\partial^{2} u}{\partial y^{2}}\right)+\frac{1}{\rho_{0} H} \tau_{x}$

$\frac{\partial v}{\partial t}+u \frac{\partial v}{\partial x}+v \frac{\partial v}{\partial y}=-\frac{1}{\rho_{0}} \frac{\partial p}{\partial y}-f u+v\left(\frac{\partial^{2} v}{\partial x^{2}}+\frac{\partial^{2} v}{\partial y^{2}}\right)+\frac{1}{\rho_{0} H} \tau_{y}$

where, $Q_{a}$ - the discharge or withdrawal $\left(\mathrm{m}^{3} / \mathrm{s}\right), H$ - the water level $(\mathrm{m}), u, v$ - velocity in $x$ and $y$ directions $(\mathrm{m} / \mathrm{s}), v-$ horizontal eddy viscosity coefficient $\left(\mathrm{m}^{2} / \mathrm{s}\right), f-$ Coriolis parameter, and $\tau_{x}, \tau_{y}-$ bottom shear stress $\left(\mathrm{N} / \mathrm{m}^{2}\right)$.

The equations were numerically solved by the alternative direction iteration (ADI) method. The daily averaged discharges and water levels were used respectively as the upstream and downstream boundary conditions. The model was cold started with an initial flow field of zero velocity (Eq. (4)) and an initial water level which submerged the entire mesh.

$u(x, y)=v(x, y)=0$.

After running for some time, the effects of the initial condition were eliminated and the outputs were used as the hot-start file for the final simulations.

\subsection{The response of fish to aquatic environment}

The behavioural response of fish to aquatic environment is usually acquired by three methods, and the most common way is to intensively net fish randomly along the studied channel. According to the fish presence frequency and the corresponding environment conditions, the relationship can be defined through the detrended correspondence analysis (DCA) or canonical correspondence analysis (CCA) methods (Katopodis, 2002; Goodwin et al., 2006; Nagaya et al., 2008). Another method is to conduct experiments in a large flume in laboratory. By observing the appearing frequency of the studied fish and the corresponding velocity, depth, the presence-velocity-depth (PVD) curve can be defined. The latest way is to track the movements of fish by acoustic PIT-Tag, to set up the relationship between fish and aquatic environment (Nestler et al, 2002; Goodwin, et al., 2006; Baigun et al., 2007).

This study adopted the approaches of field netting and laboratory experiments to define the PDV curves for the grass carp and crucian carp.

\subsection{Fish model}

On the basis of the flow module, an individual-based fish population dynamic module was developed in the study. The module consists mainly of the growth and movement.

\subsubsection{The growth equation}

According to the life cycle of fish, the growth of fish can be divided into six different stages (Fig. 2): egg, larva, juvenile, young, adult, and aged or senility. The properties of sex, mating and reproduction of fish have not been considered yet.

To model the growth of fish, this research applied the Von Bertalanffy (Von Bertalanffy, 1938; Fontoura and Agostinho, 1996) equation, which describes growth from the angle of metabolism. The growth of length is given as:

$l_{t}=L_{\infty}\left(1-e^{-k\left(t-t_{0}\right)}\right)$

Let $W_{t}=a l_{t}^{3}$ and $W_{\infty}=a l_{\infty}^{3}$, the growth of weight is given by:

$$
W_{t}=W_{\infty}\left(1-e^{-k\left(t-t_{0}\right)}\right)^{3}
$$
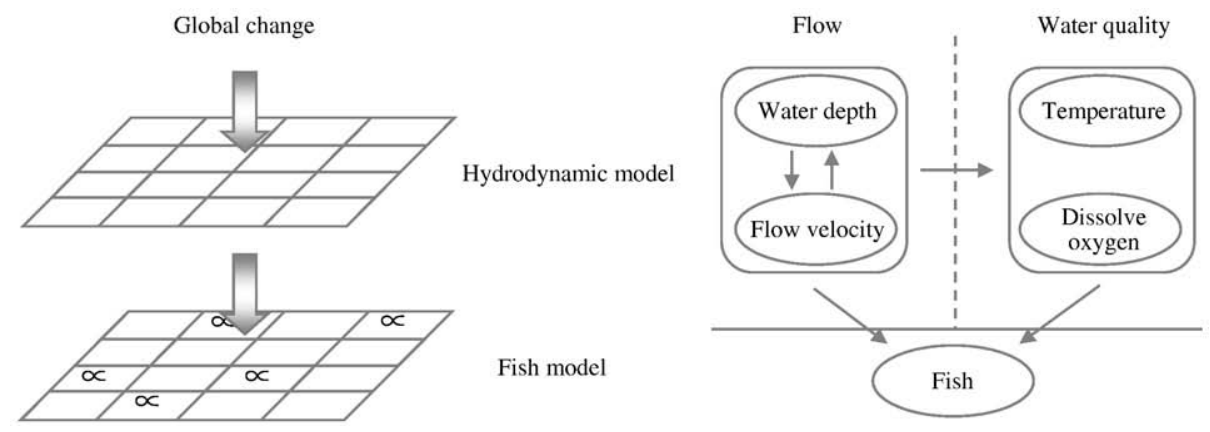

Fig. 1. Model framework. 


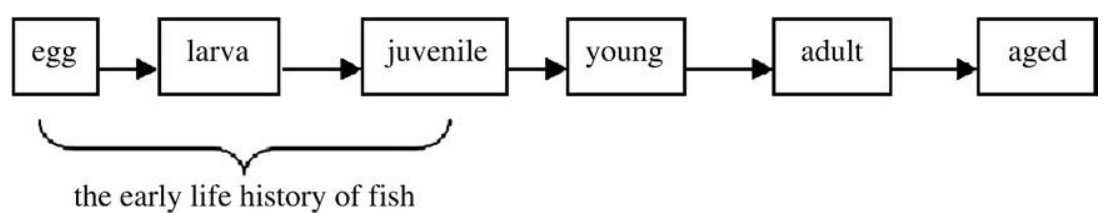

Fig. 2. The life cycle of fish.

where $t$ is age; $l_{t}$ and $W_{t}$ are average length and weight at age $t ; l_{\infty}$ and $W_{\infty}$ are average ultimate length and weight; $k$ is growth parameter, which determines the rate at which the function approaches to its limit; and $t_{0}$ as the supposed beginning age.

\subsubsection{The movement rules}

The movements of fish determine their spatial distribution in the river, which is an important objective of aquatic ecosystem modelling (Steven et al., 1999). Without the effects of food stress and predation/ escaping, the movements are dependent on the aquatic environment conditions. Taking the simulated flow conditions from the 2dimensional module as inputs and using the defined response curves, the possibilities of fish moving into the neighbouring nine grids were calculated. After that, a random selection process determined the final movement.

Fig. 3 illustrated the current fish distribution and the possible movements in the next time step, where indicated the possible target grids that fish $\nabla$ might move in. Fig. 4 showed the moving rules implemented in the model. In principal, there were nine possible choices for an individual fish; however, in this case only three were suitable according to the flow conditions (Fig. 4, left). Considering the grouping behaviour of fish, the model would choose the grid having the largest number of the same type of fish among the three options, and the individual would move to the selected grid. If there were several such grids, the individual would randomly move to one of them (Fig. 4, right). After the movement, the fish would be assigned the new position ( $x$ and $y$ ).

However, a water area can only accommodate a limited amount of fish, and this means that if the number of fish in a grid reaches to the carrying capacity, the preference of fish moving into the grid no longer exists.

\subsubsection{Boundary conditions}

Similar to any model, there must be boundaries of the fish module. Along the river banks, close boundary was applied, saying that no fish moved out of water (Fig. 5).

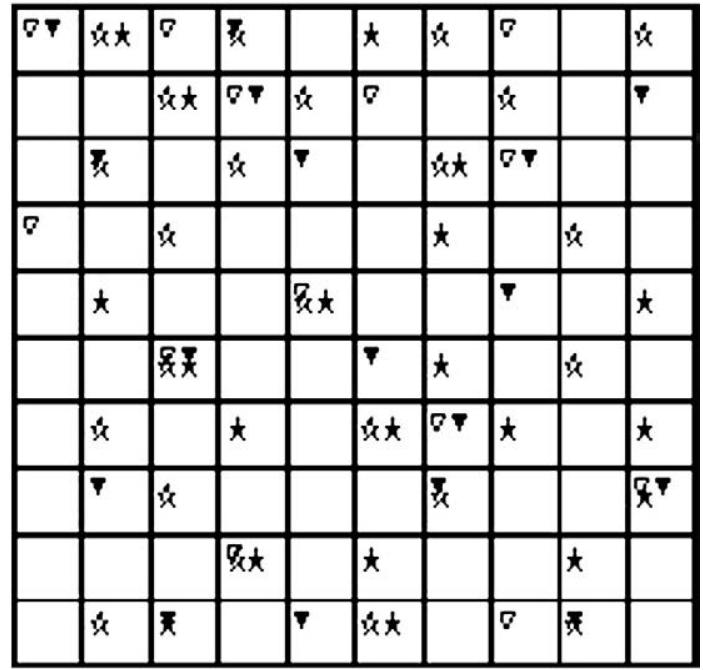

Fig. 3. Illustration of aquatic environment conditions and fish distribution ( $\nabla$ and $\boldsymbol{\nabla}$ indicate two different fishes; 放 and $\star$ indicate the possible target grids to move in).
At the upstream and downstream cross-sections, open boundary that follows Poisson process (Eq. (7)) was applied.

$P_{t}(n)=\frac{\lambda^{n}}{n !} e^{-\lambda}$

where $n$ is the number of individuals crossing the boundary, $n>0 ; \lambda$ is parameter, and $t$ is time period. The parameter $\lambda$ of the Poisson distribution was estimated by maximum-likelihood method using the data collected from the field fish netting. At each time step, two random numbers (moving in and out) subjected to the estimated Poisson distribution was generated for each boundary. The fish coming into the computation domain was randomly distributed in the grids where the environmental condition was suitable. The individuals that were closest to the boundary and lived in unsuitable conditions would swim out first, and then the others, until the number of individuals swimming out reached to the generated number.

The initial condition was defined by randomly distributing a certain amount of fish in the computation domain.

\section{Model application}

\subsection{Study area}

The developed model was applied to the compound channel near the Yangshuo station of the Lijiang River, which is located in the southwest China (Fig. 6). Due to the special Karst landscape and the
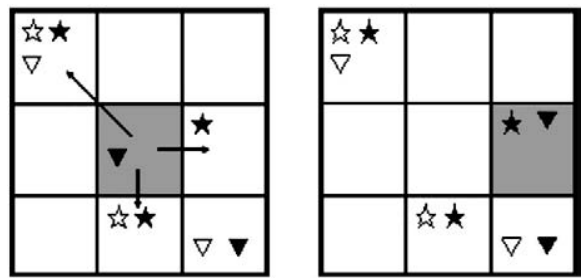

Fig. 4. Illustration of fish movement rules of the model (left: pre-movement; right: after movement. $\nabla$ and $\mathbf{\nabla}$, is and $\star$ have the same notation as Fig. 3 ).
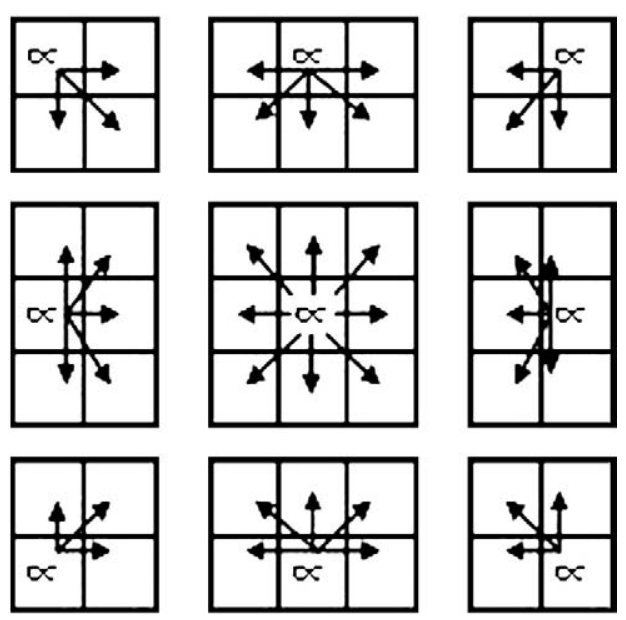

Fig. 5. Treatment of the boundary along the river banks. 

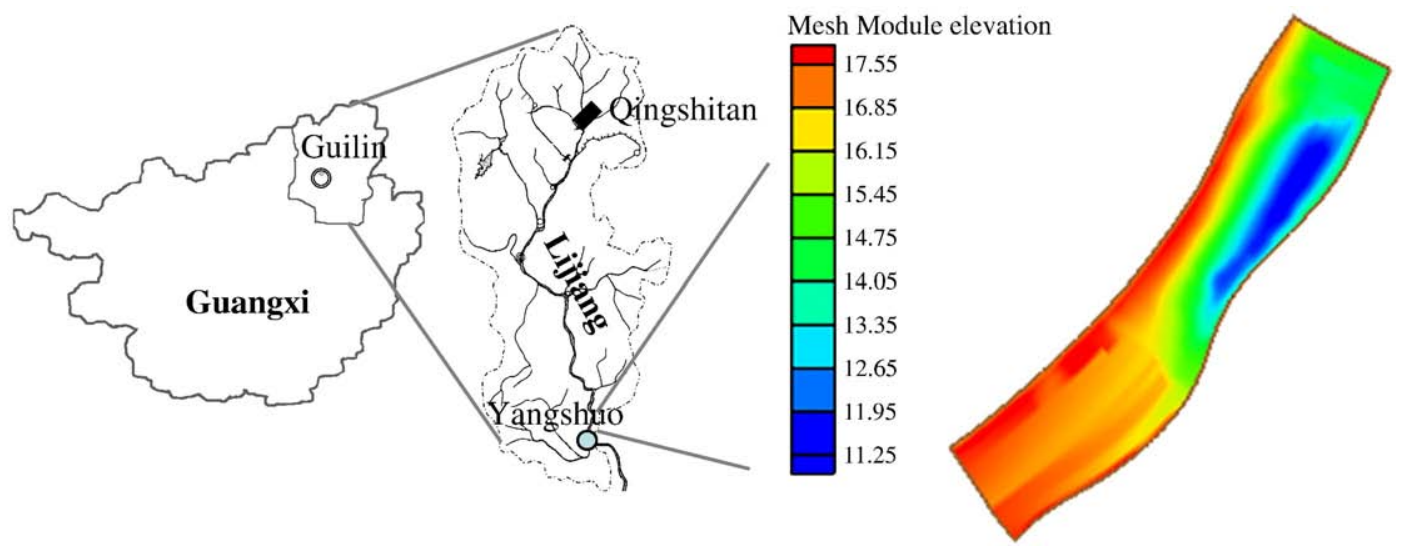

Fig. 6. The studied area and the bathymetry of the river section.

strong seasonality of rainfall, the discharges at the Yangshuo station vary from $12 \mathrm{~m}^{3} / \mathrm{s}$ to $12,000 \mathrm{~m}^{3} / \mathrm{s}$ with an annual average of $120 \mathrm{~m}^{3} / \mathrm{s}$. The recorded minimum discharge was $8 \mathrm{~m}^{3} / \mathrm{s}$, which imposed great threats to the local water supply and aquatic ecosystem. More important, the tourism is the predominant income of the local economy. When the discharge is lower than $30 \mathrm{~m}^{3} / \mathrm{s}$ at the Guilin hydrologic station, the cruiser cannot navigate to the world-famous Yangshuo resort. During the dry period from October to next March, there is a serious problem of cruise, thus affects the local economy. Therefore, a series of reservoirs have been or will be constructed in the main stream and tributaries in the upstream. At the moment, only the Qingshitan Reservoir is under operation.

When all the reservoirs are in operation, the low flow during dry season is expected to reach $60 \mathrm{~m}^{3} / \mathrm{s}$. Since the flow regimes have been dramatically altered by the Qingshitan Reservoir and will be further modified, it is important to quantitatively evaluate the influences on the downstream aquatic ecosystem and seek for possible optimisation scheme to reduce or remediate the impacts. Such studies cover flow condition changes ( $\mathrm{Li}$ et al., 2008, 2009), riparian vegetation successions (Chen and Ye, 2008; Ye et al., 2008, 2009), and fish population dynamics presented in this paper.

\subsection{Model configuration}

The bathymetry and the flow profiles of the compound channel were measured by the Doppler flow measurement device - River Cat, which is manufactured by the SonTek/YSI. In total, 15 cross-sections were measured and the data for the entire area were obtained by linear interpolation (Fig. 6). For the hydrodynamic simulation, the curvilinear grid was used and the time step was set $15 \mathrm{~min}$. The outputs were 12 hours (half-daily) averaged water level and flow velocity.

The modelled fishes were grass carp and crucian carp that are dominant species in the Lijiang River and are important for local fishery. The responses of the two species to the aquatic environment were acquired through in-situ survey, laboratory flume experiment and the related literatures. For example, in the flume (Fig. 7, top), many video cameras and flow (velocity and depth) meters were installed. Fishes were released in the flume. The flow conditions were varied by changing the discharge. The videos were analyzed to count how long the fish group stayed at a certain place (Fig. 7, bottom left). Meanwhile, the flow condition at each place was obtained through the data measured by the meters. By using the corresponding flow
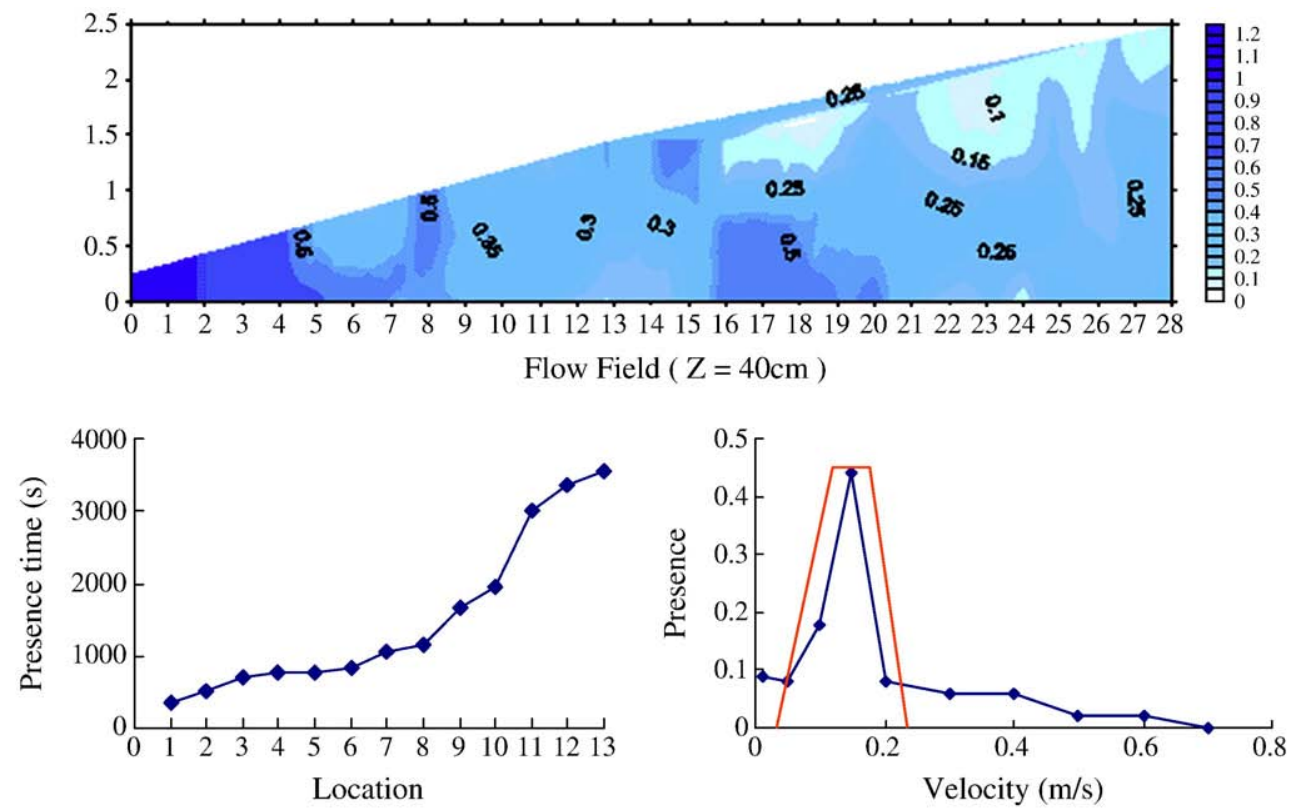

Fig. 7. The illustration of flume experiment (top: flow field; bottom: response curve). 

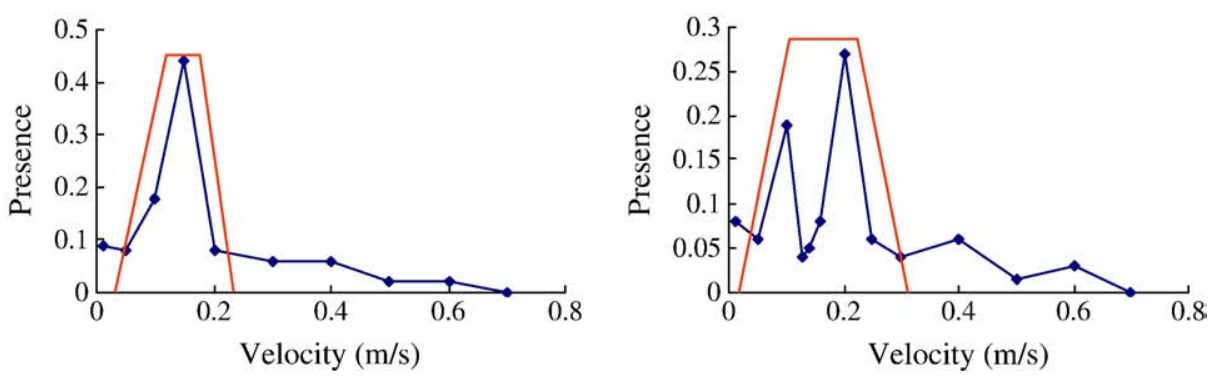

Fig. 8. The PVD curve acquired from experiments (left: grass carp; right: crucian carp).

condition at each location, the PVD curve is defined (Fig. 7, bottom right and Fig. 8). The same experiments were conducted for the other factors.

Although the developed model has the capability to incorporate a number of water quality factors (such as T, DO, and SS) that affect fish movement, only the curves of fish response to flow conditions had been completed up to now; thus the effects of water quality were not included in the current paper. The experiments about fish response to water quality parameters are ongoing in China Three Gorges University; therefore, they will be implemented in the forthcoming study.

The values of the growth parameter were obtained through lab cultural experiments (Fig. 9) and are given in Table 1. The water quality effects on growth function were not considered in the current model. The time step of the simulation was 0.5 day, and at each step the fish dynamic module read in the outputs from the two-dimensional water quality module.

Fish is different from aquatic plants because it has active movement, and the distribution is affected by the locations of spawning ground, feeding ground and wintering ground. Besides, the methods for field fish sampling are limited and the surveyed data contain high randomness and uncertainties. Therefore, it is usually difficult to model the exact population and distribution of the fish, thus the study focused on the relative changes induced by the flow regulations. In accordance, the initial condition of the simulations was defined by randomly distributing a certain amount of grass carps and crucian carps in the studied channel. The model applied an open boundary that follows Poisson process at the upstream and downstream crosssections, and the parameter values $\lambda$ were estimated from the field observations that were collected by continuous fish netting. Basing on the data in the last 35 years, the averaged biomass density of the two fishes was about $43.66 \mathrm{~g} / \mathrm{m}^{2}$, which means that a unit water area (128.92 $\mathrm{m}^{2} /$ grid in the model) can accommodate 4 adult grass carp individuals or 34 adult crucian carps. The detailed model configuration is given in Table 2 .

\subsection{Model results}

The model simulated three scenarios: the typical dry year (1979) before reservoir operation as reference, the typical dry year (2004) after reservoir operation, and the year 2004 assuming no regulation. The simulation snapshots of the three scenarios are given in Figs. 10-12. The results were compared with the historical and current field data of spatially relative fish catching rate. In such a way, the model performance was validated, because there was no exact fish population data available for model verification.

It was seen that although the fish individuals were randomly distributed at the beginning, they moved towards different areas according to the suitability of the aquatic environment conditions at different life stages. As the simulations went on, the results exhibited obvious habitual gregarious behaviour that different types of fish tend to choose their own habitats and grouped gradually. It was noticed that the crucian carps grouped more evidently than grass carps, because the unit carrying capacity was larger for the crucian carp than for grass carp. The simulated fish distribution patterns in the reference year 1979 and the year 2004 with regulations were comparable to the historical data from annual fishery survey (Feng, 1985). This indicated that it was reliable to apply the model to investigate the effects of
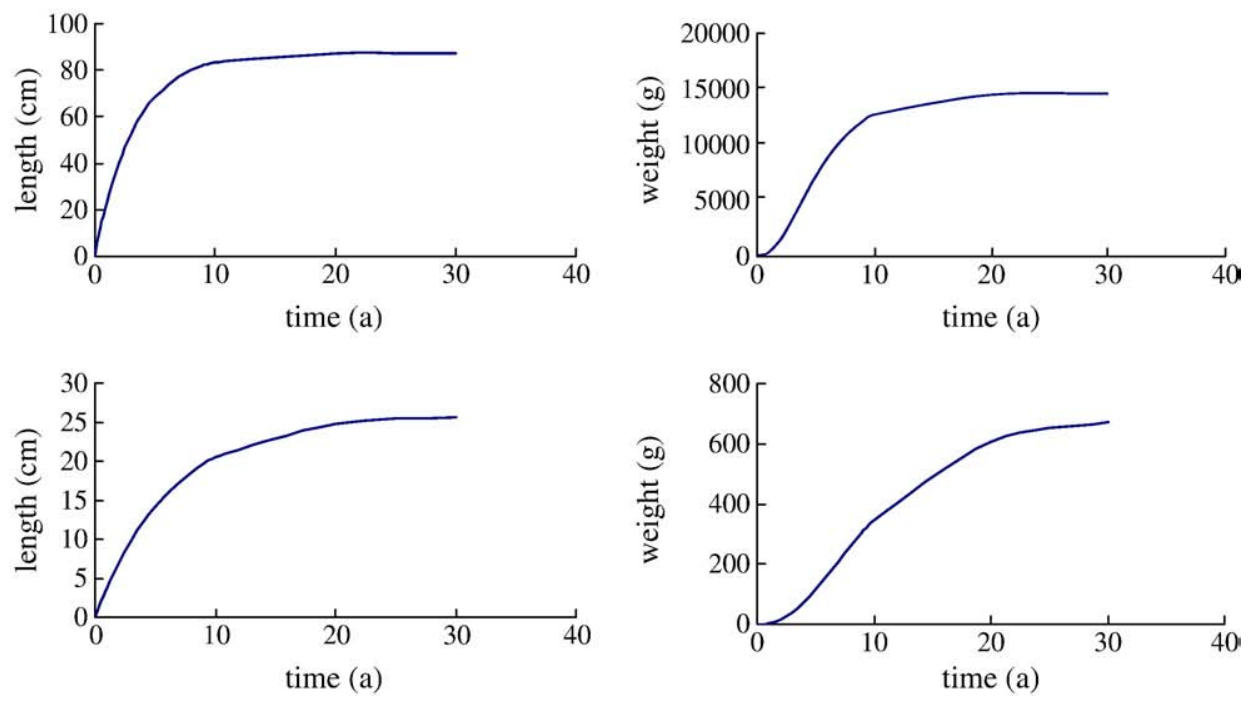

Fig. 9. The growth curves of fish (up: grass carp; down: crucian carp). 
Table 1

Parameter value used in the fish dynamic module.

\begin{tabular}{|c|c|c|c|c|}
\hline & & Grass carp & Crucian carp & Notes \\
\hline \multirow[t]{6}{*}{ Life cycle } & Egg (day) & $1-2$ & $2.625-3.125$ & \\
\hline & Larva (day) & $3-4$ & 6 & \\
\hline & Juvenile (day) & 30 & 30 & \\
\hline & Young (year) & $1-2$ & 2 & \\
\hline & Adult (year) & 3.8 & 6 & \\
\hline & Senility (year) & $7-8$ & 7 & \\
\hline \multirow[t]{2}{*}{ Growth equation } & Length $(\mathrm{cm})$ & $L_{t}=87.2\left(1-e^{-0.31\left(t-t_{0}\right)}\right)$ & $L_{t}=25.8\left(1-e^{-0.16\left(t-t_{0}\right)}\right)$ & Lab experiments \\
\hline & Weight (g) & $W_{t}=14489.2\left(1-e^{-0.31\left(t-t_{0}\right)}\right)^{3}$ & $W_{t}=687.7\left(1-e^{-0.16\left(t-t_{0}\right)}\right)^{3}$ & \\
\hline \multirow[t]{6}{*}{ Appropriate water depth (m) } & Egg & - & - & No movement in the water (Yin, 1995) \\
\hline & Larva & - & - & \\
\hline & Juvenile & $0.7-1.2$ & $0.7-1.2$ & \\
\hline & Young & $1.2-2.5$ & $1.2-2.5$ & \\
\hline & Adult & $2.0-2.5$ & $2.0-2.5$ & \\
\hline & Senility & $1.8-2.2$ & $1.8-2.2$ & \\
\hline Appropriate velocity (m/s) & & $0.07-0.12,0.16-0.24$ & $0.06-0.20$ & $\alpha$-cut $(\alpha=0.1)$ \\
\hline
\end{tabular}

reservoir regulations by comparing the two scenarios (real situation and assuming no regulation) in 2004.

To quantitatively evaluate the impacts of flow regulations on fish population dynamics, further analyses on the modelled data were conducted. The simulated populations and total biomass of the simulated scenarios were presented in the Figs. 13 and 14.

The sudden increase of populations was because of the development of larva into juvenile which the population counted from, and the process took time only of days. However, the biomass did not have sharp increase correspondingly because juvenile individual had small weight.

It was found from Fig. 13 that even starting from exactly the same initial condition, the total population and biomass of both species in 2004 without regulation effects were higher than in 1979, in particular for grass carp. Such discrepancy became more obvious after June. The main reason was the intrinsic difference of the hydrological conditions.

In Fig. 14, the population and biomass of grass carp with reservoir regulation were larger than that without regulation, which indicated that the flow regulation, in particular the water recharge in dry season, had positive effect on the grass carp. The positive effect may be because of the increase of water depth and habitat space during the dry period. For crucian carp, an opposite phenomena was observed, but the difference was very small. Therefore, the flow regulation has little effect on crucian carp.

It is important to notice that from early April to end of May, the flow regulation had negative impacts on the grass carp populations (Fig. 14). The reason might be the increase of flow velocity that jeopardized the development of larva and juvenile into young fish. Therefore, the reservoir operation should be improved during this period.

The model presented here was further developed from the previous version (Chen et al., 2009b). In the previous model, the upstream and downstream boundaries were closed, which meant no fish moved in or out. These artificial barriers were absolutely unrealistic. The movement rules were purely dependent on the flow conditions, which were quite different from the fact that fish had grouping behaviour. The same habitat requirements were applied to all individuals despite their different life stages. Fig. 15 showed the

Table 2

Initial population and boundary conditions.

\begin{tabular}{lllllllr}
\hline & Larva & Juvenile & Young & Adult & Senility & $\lambda$ & $K^{\text {a }}$ \\
\hline Grass carp & 100 & 100 & 100 & 100 & 100 & 1 & 4 \\
Crucian carp & 900 & 800 & 800 & 800 & 800 & 4 & 34 \\
\hline
\end{tabular}

a Estimated from the data in the last 35 years (Feng, 1985). results from the previous model using exactly the same simulation configurations.

In the current model, Poison process was applied to the upstream and downstream boundaries. When the ambient conditions were the same, the fish moved to the group of the same type, but was limited by carrying capacity of unit area. For each life stage, average life span was applied and different stages had different habitat requirements (Table 1), thus the age effects were considered.

Since the Lijiang River is predominant by the surface runoff, the reservoir regulations reduced the peak discharge in wet season and extend its duration by reservoir storage, while increased the minimum discharge in dry season and shortened its duration by reservoir release for navigation. Therefore, the risk that fish were stranded in the floodplain during the flooding period was alleviated. Meanwhile, the increase of discharge in dry period can enlarge the water surface area and hence improve the fish habitat for wintering and spawning. As a result, if only the flow aspect is concerned, the alternation of hydrological regimes by the Qingshitan Reservoir has positive effects on the non-migrating fishes of bigger size (e.g. grass carp), which requires larger water area and depth. However, the study indicated that the reservoir regulation scheme from April to June should be improved.

\section{Discussion}

Basing on the previous research (Chen et al., 2009b), the study further developed the individual-based fish model and integrated it with a two-dimensional flow model to investigate the impacts of reservoir operations on the downstream aquatic ecosystem. The approach efficiently characterized the difference of the fish individual properties and actions. The property differences were represented by the length, weight and age, and the action difference was represented by the grouping, escaping, and the response to flow conditions.

The model was applied to a compound channel of the Lijiang River, which was affected by the upstream Qingshitan Reservoir. It was found that the flow regulation had positive effects on grass carp in the downstream if only the flow aspect was concerned. However, the simulation indicated that the present operation scheme during April to June should be improved. Since the current model has not considered the aspects of food stress and harvesting, the simulated absolute values of fish number and biomass are different from the fishery survey. However, the spatial distribution patterns and the tendency of changes were relatively close.

Although there are many factors affecting the fish population dynamics, usually only few are dominant for a specific case. The present model considered the water depth and flow velocity whose experiments have been completed. In addition, the effect of fish age 

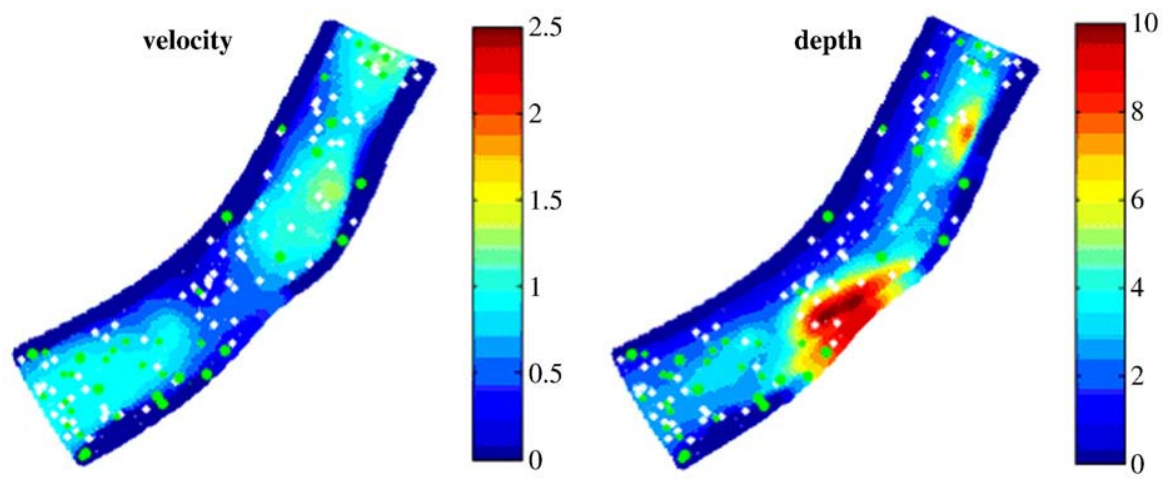

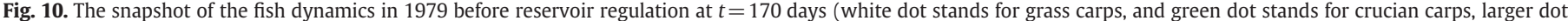
means more grouped individuals. The same notation is for Figs. 11-12).
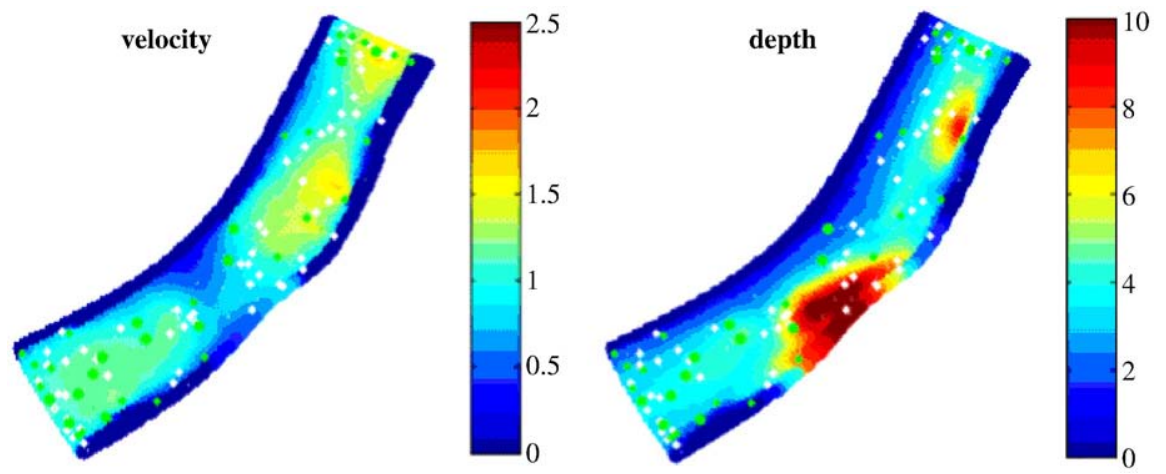

Fig. 11. The snapshot of fish dynamics in 2004 with reservoir regulations at $t=170$ days.
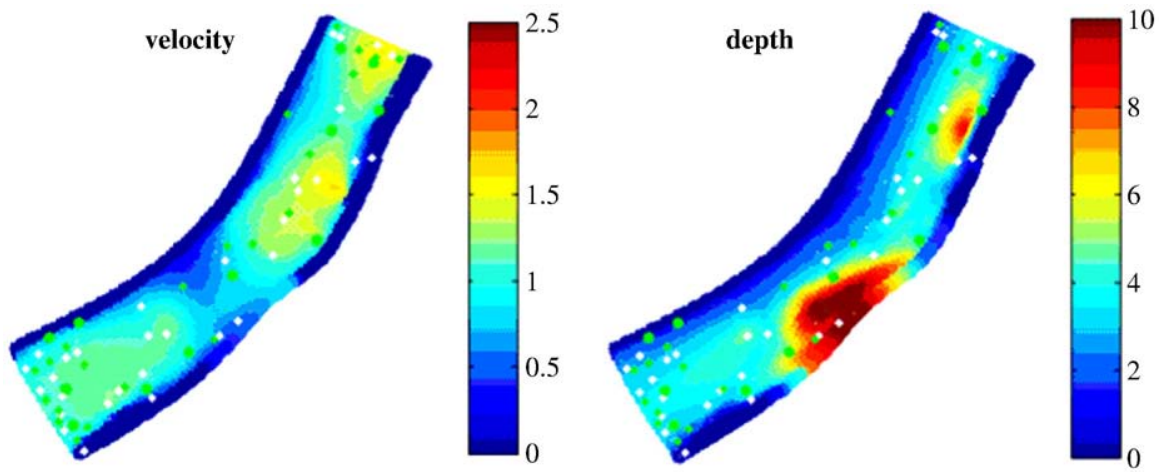

Fig. 12. The snapshot of fish dynamics in 2004 assuming no reservoir regulations at $t=170$ days.
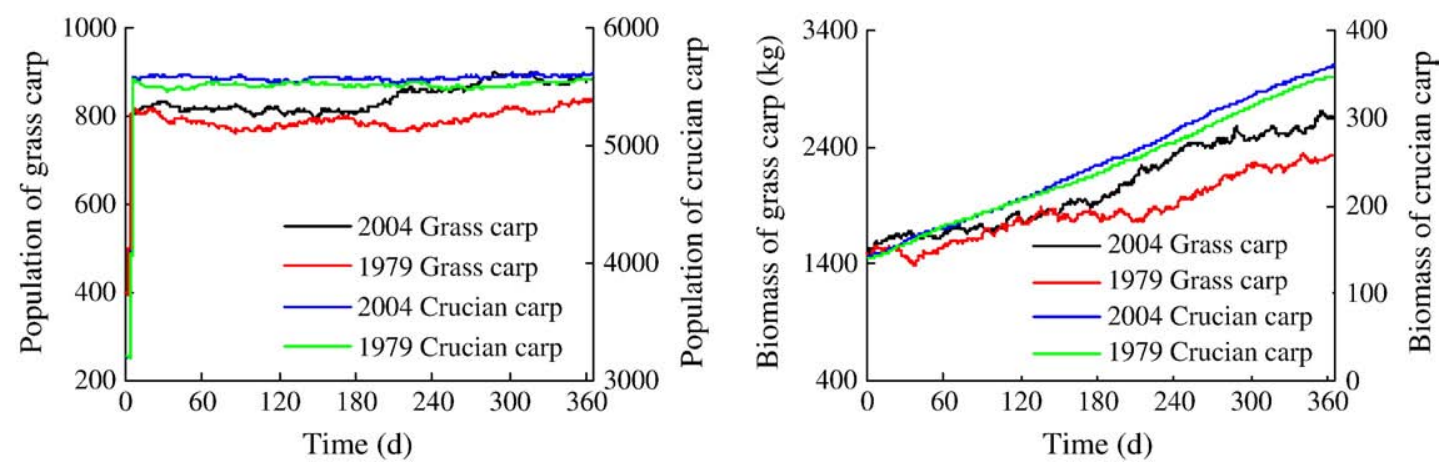

Fig. 13. Comparisons of the fish populations and biomass between 1979 and 2004 . 

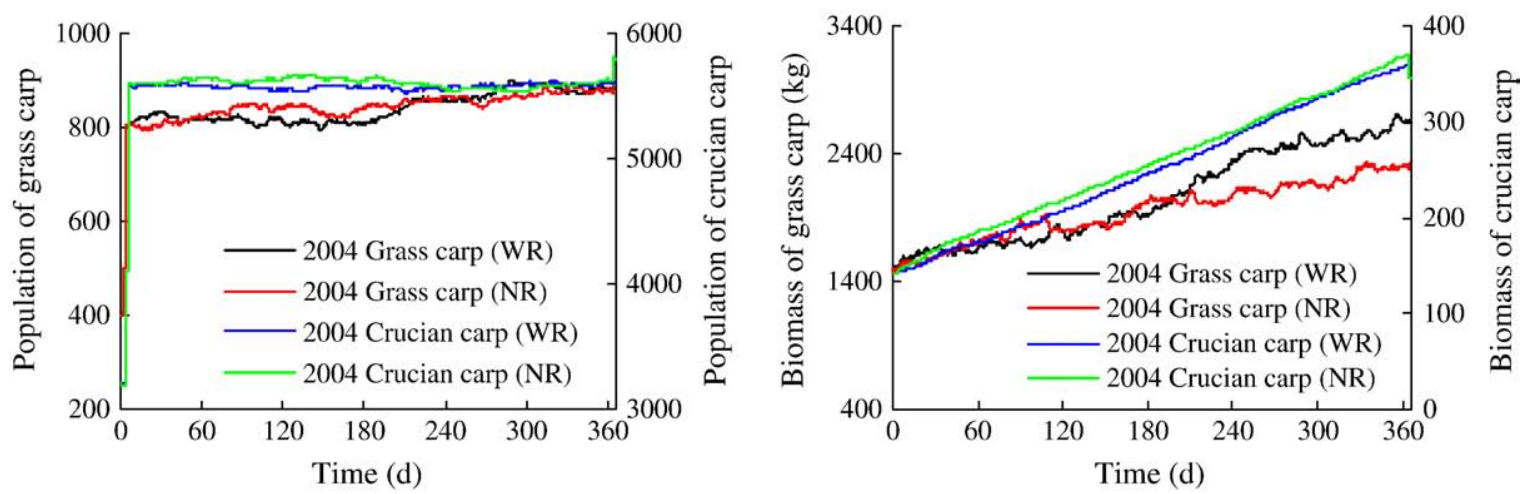

Fig. 14. Comparisons of the fish populations and biomass in 2004 with regulation (WR) and no regulation (NR).
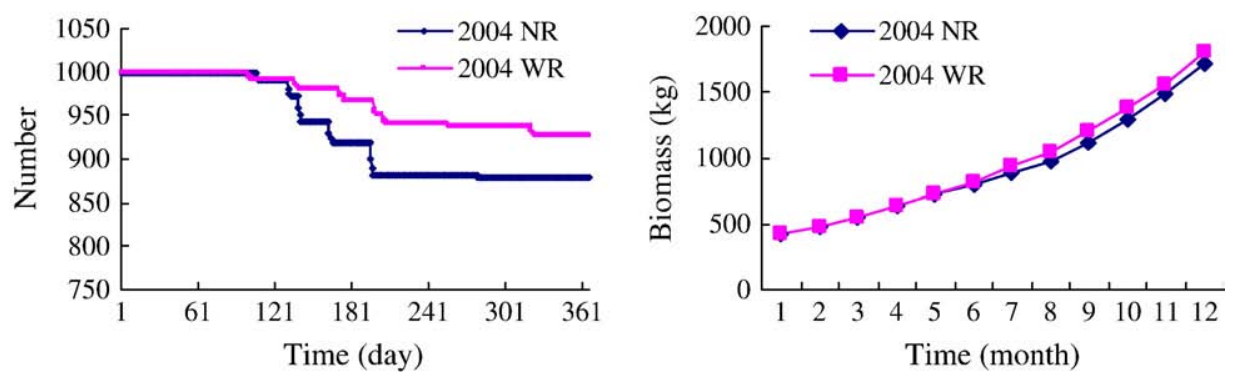

Fig. 15. The simulation results of grass carp by the previous model (Chen et al., 2009b).

was taken into account because for one fish, the responses to the same environmental changes are distinct at different life stages. In the forthcoming study, the water temperature, dissolved oxygen and suspended substance whose experiments are ongoing will be incorporated. The undergoing development also included the aspect of food stress. In addition, the constant growth rate was applied in the current study; however, the growth rate has been changed into a time-dependent function, saying a different growth rate is used at a different life stage.

Compared to 3D model, 2D model does not have vertical position of the fish. However, it should not be regarded as a disadvantage when a river channel is of concern, because $2 \mathrm{D}$ model can provide enough information in such a case. The model complexity will be enormously increased in 3D system since 27 neighbouring grids are available for possible movement. In addition, there is almost no 3D fish distribution data for model calibration and validation. Of course, for deep lakes and reservoirs, 3D model would be more suitable than 2D model, and 3D fish position tracking data need to be collected specifically.

It has been well recognized that flow regulations change the sediment flux and thus the bed formation, which has significant effects on fish habitat. In our model system, a 2D sediment transportmorphological dynamic module is under integration, which has been presented in Ye et al (2009). The changes of flow rate affect the sediment transport and then the river morphology, which affect the riparian vegetation. Meanwhile, the changes of riparian vegetation affect the flow field through roughness, then the sediment transport and morphology.

\section{Acknowledgments}

The study was supported by the National Natural Sciences Foundation of China (No. 50639070 and No. 50879086) and the Guangxi Water Resources Department.

\section{References}

Baigun, C.R.M., Nestler, J.M., Oldani, N.O., Goodwin, R.A., Weber, L.J., 2007. Can North American fish passage tools work for South American migratory fishes? Neotropical Ichthyology 5 (2), 109-119.

Bovee, K.D., 1982. A guide to stream habitat analysis using the instream flow incremental methodology. Instream Flow Information, US Fish and Wildlife Service, Fort Collins, Colorado. 248

Charles, S., Subtil, F., Kielbassa, J., Pony, D., 2008. An individual-based model to describe a bullhead population dynamics including temperature variations. Ecological Modelling 215, 377-392.

Chen, Q., 2004. Cellular Automata and Artificial Intelligence in Ecohydraulics Modelling. Taylor \& Francis Group plc, London UK.

Chen, Q., Ye, F., 2008. Unstructured Cellular Automata and the Application to Model River Riparian Vegetation Dynamics. Lecture Notes in Computer Science 5191, 337-344.

Chen, Q., Ye, F., Li, W., 2009a. Cellular automata based ecological and ecohydraulics modeling. Journal of Hydroinformatics 11 (3-4), 252-265.

Chen, Q., Cheng, Z., Cai, D., Wu, S., 2009b. Analyses of the downstream fish response to reservoir operation using individual-based model. Journal of Hydraulics Engineering 40 (8), 897-903 in Chinese with English abstract.

Clark, M.E., Rose, K.A., 1997. Individual-based model of sympatric populations of stream resident rainbow trout and brook char: model description, corroboration, and effects of sympatry and spawning season duration. Ecological Modelling 94, 157-175.

DeAngelis, D.L., Gross, L.J., 1992. Individual-based Models and Approaches in Ecology. Chapman and Hall, New York.

DeAngelis, D.L., Rose, K.A., Huston, M.A., 1994. Individual oriented approaches to modeling populations and communities. In: Levin, S.A. (Ed.), Frontiers in Mathematical Biology. : Lecture Notes in Biomathematics, vol. 100. SpringerVerlag, New York, pp. 390-410.

Dong, Q., DeAngelis, D.L., 1998. Population consequences of cannibalism and competition for food in a smallmouth bass population: an individual-based modeling study. Transactions of the American Fisheries Society 127, 174-191.

Duel, H., van der Lee, G.E.M., Penning, W.E., 2002. Habitat modelling of rivers and lakes in The Netherlands: an ecosystem approach. Canadian Water Resources Journal 28, 231-248.

Feng, B., 1985. Guangxi Freshwater Fishery. China Agricultural Press. 27pp (in Chinese). Fontoura, N.F., Agostinho, A.A., 1996. Growth with seasonally varying temperatures: an expansion of the Von Bertalanffy growth model. Journal of Fish Biology 48, 569-584.

Goodwin, R.A., Nestler, J.M., Anderson, J.J., Weber, L.J., Loucks, D.P., 2006. Forecasting 3-D fish movement behavior using a Eulerian-Lagrangian-agent method (ELAM). Ecological Modelling 192, 197-223.

Holm, C.F., Armstrong, J.D., Gilvear, D.J., 2001. Investigating a major assumption of predictive instream habitat models: is water velocity preference of juvenile Atlantic salmon independent of discharge? Journal of Fish Biology 59, 1653-1666. 
Katopodis, C., 2002. Developing a toolkit for fish passage and fish habitat projects. In: King, J., Jorde, K. (Eds.), Proceedings of the 4th International Ecohydraulics Symposium, Cape Town, South Africa (CD Rom).

Kitazawa, D., Tabeta, S., Kato, T., Ruardij, P., 2008. A comparative study of the biomassbased and individual based model of blue mussels. Ecological Modelling 215, 93-104

Li, R., Chen, Q., Mynett, A.E., Wu, S., Wang, H., 2008. Modelling of the flow changes due to reservoir operations and the impacts on aquatic ecosystem downstream. Proceedings of the 16th IAHR-APD Conference, Nanjing, China, Vol. VI: 2272-2278.

Li, R., Chen, Q., Cai, D., Wang, H., 2009. One-dimensional and two-dimensional coupled water environment model for studying the impact of upstream reservoir operation. Journal of Hydraulics Engineering 40 (7), 769-775 (in Chinese with English abstract).

Liem, K.F., 1995. Introducing fishes. In: Paxton, J.R., Ecschmeyer, W.N. (Eds.), Encyclopedia of Fishes. Academic Press, San Diego, pp. 14-19.

Morales-Chaves, Y., 2004. Analysis of mussel population dynamics in the Mississippi River. PhD Thesis, Civil and Environmental Engineering, University of Iowa, Iowa City.

Nagaya, T., Shiraishi, Y., Onitsuka, K., Higashino, M., Takami, T., Otsuka, N., Akiyama, J., Ozeki, H., 2008. Evaluation of suitable hydraulic conditions for spawning of ayu with horizontal 2D numerical simulation and PHABSIM. Ecological Modelling 215, 134-143.

Nestler, J., Parasiewicz, P., Poff, N.L., Bowen, Z., 2002. First principles based attributes for describing a template to develop the reference river. In: King, J., Jorde, K. (Eds.), Proceedings of the 4th International Ecohydraulics Symposium, Cape Town, South Africa (CD Rom).

O'Callaghan, M., Gordon, G.N.G., 2008. An individual-based stochastic hazard model of eastern king prawn (Melicertus plebejus) migration with spatially and temporally varying fishing effort. Ecological Modelling 218, 73-94.
Rose, K.A., Chrisensen, S.W., DeAngelis, D.L., 1993. Individual based modelling of populations with high mortality: a new method based on following a fixed number of model individuals. Ecological Modelling 68, 273-292.

Shields, F.D., Knight, S.S., Cooper, C.M., 1997. Rehabilitation of warmwater stream ecosystems following channel incision. Ecological Engineering 8, 93-116.

Shuler, S.W., Nehring, R.B., 1993. Using the physical habitat simulation model to evaluate a stream habitat enhancement project. Rivers 4, 175-193.

Steven, F, Railsback, R.H., Lamberson, B.C., Walter, E.D., 1999. Movement rules for individual-based models of stream fish. Ecological Modelling 123 (2-3), 73-89.

Tollefson, J., 2008. Salmon study sparks row over dams. Nature 455, 1160.

Tyler, J.A., Rose, K.A., 1994. Individual variability and special heterogeneity in fish population models. Reviews in Fish Biology and Fisheries 4, 91-123.

Van Winkle, W., Rose, K.A., Chambers, R.C., 1993. Individual-based approaches to fish population dynamics: an overview. Transactions of the American Fisheries Society 122, 397-403.

Von Bertalanffy, L., 1938. A quantitative theory of organic growth (Inquiries on growth laws. II). Human Biology 10, 181-213.

Ye, F., Chen, Q., Wu, S., Cai, D., 2008. Spatially-explicit modelling of riparian vegetation dynamics under reservoir operations. Acta Ecologica Sinica 28 (6), 7-16 (in Chinese with English abstract).

Ye, F., Chen, Q., Li, R., 2009. Modelling the riparian vegetation evolution due to flow regulation of Lijiang River by unstructured cellular automata. Ecological Informatics. doi:10.1016/j.ecoinf.2009.08.002.

Yin, M., 1995. Fish Ecology. China Agricultural Press. (in Chinese). 